\title{
Caudate nucleus lesions and active avoidance: A reply to Winocur
}

\author{
ROBERT J. KIRKBY \\ Lincoln Institute, Melbourne, Australia 3053 \\ and \\ STEPHEN POLGAR \\ Sydney University, Sydney, N.S.W., Australia 2000
}

\begin{abstract}
Investigations of the effects of anterodorsal caudate nucleus lesions on one-way and two-way active avoidance learning in the rat have resulted in contradictory findings. It was suggested that this disagreement might be associated with differences in experimental variables such as number of trials per testing session, lesion size, CS-UCS intervals, and shock intensity. Kirkby's interpretation of the role of the caudate in the modulation of neural arousal was reviewed.
\end{abstract}

In 1969 Winocur and Mills reported that lesions of the anterodorsal caudate nucleus did not impair active avoidance in the rat. Kirkby and Polgar (1974) carried out a series of experiments showing that the rats with lesions restricted to the anterodorsal caudate nucleus were impaired in learning one-way and two-way active avoidance under several conditions. About the same time Winocur (1974) reported further experiments showing that rats with lesions of the anterodorsal caudate nucleus were impaired in learning a two-way, but not a one-way, active avoidance problem. Most recent in this series has been Winocur's (1975) criticism of the Kirkby and Polgar (1974) investigations. The present paper replies to some of the points raised by Winocur.

So far, two studies have indicated that lesions restricted to the anterodorsal caudate nucleus impair one-way active avoidance learning (Kirkby \& Kimble, 1968; Kirkby \& Polgar, 1974, see p. 306) and two studies have indicated that such lesions do not impair one-way active avoidance (Winocur, 1974; Winocur \& Mills, 1969). We suggest that differences in experimental variables could account for discrepancies in these studies. Four such differences are: (1) Number of trials per testing session may be a relevant variable. Kirkby and Kimble (1968) and Kirkby and Polgar (1974) reported deficits with few trials per day (6 and 10 trials per day, respectively), while Winocur (1974) and Winocur and Mills (1969) did not find deficits when 15 trials per day were given. This is particularly important in the light of the reports indicating that caudate-damaged subjects tend to suffer from a "warm-up" deficit in avoidance learning and perform particularly poorly in the earlier trials of each testing session (Coyle, Kirkby, \& Polgar, 1973; Green, Beatty, \& Schwartzbaum, 1967). (2) Lesion size, given that it is confined to the anterodorsal caudate nucleus, could also determine the degree of the deficit in one-way active avoidance. In a study where the anterior caudate lesions were very large (Kirkby \& Kimble, 1968), deficits were very marked, notwithstanding that some of these lesions destroyed posterior caudate tissue as well. (3) The CS-UCS interval may be an important variable for exposing deficits in one-way avoidance following caudate lesions. Vanderwolf (1962) has shown that lengthening the CS-UCS interval can considerably improve avoidance decrements associated with some types of brain damage. (4) As was indicated by Kirkby and Polgar (1974, Experiment 2), shock intensity may be critical in determining the degree of one-way deficit following caudate nucleus lesions. This possibility is strongly supported by the findings of Thomas and Hill (1973).

We do not accept Winocur's assertion that anterodorsal portions of the caudate nucleus are not involved in one-way avoidance learning. Quite possibly several areas of the caudate nucleus modulate active avoidance. Under very specific conditions, both anterodorsal and posteroventral caudate lesions may result in avoidance impairments; however, the experimental conditions under which these deficits occur need not necessarily coincide.

Winocur (1975) made several criticisms of Kirkby's interpretation of the role of the caudate nucleus in the modulation of neural arousal (Kirkby, 1973). These included comments on the possible transient nature of the hyperreactivity observed after lesions of the caudate nucleus and on the functional homogeneity of the caudate nucleus.

Winocur raised the interesting point that Kirkby's 1973 studies were carried out within 28 days of surgery and that experiments extended over a longer time might have shown that the hyperreactivity seen in the caudate-lesion rats was transient. This could be true; however, it has been found that rats with lesions of the 
anterodorsal regions of the caudate nuclei were hyperreactive to several types of stimuli including stimulant and convulsant drugs as late as 70 days after surgery (Kirkby, 1971).

As regards the functional homogeneity of the caudate, we find Winocur's interpretation of the Kirkby (1973) paper rather surprising. As Winocur (1975) correctly observed, Kirkby did suggest that "the caudate nucleus plays a role in the modulation of neural arousal." However, it requires an extremely broad interpretation to view this statement as "a unitary explanation of caudate function" or even a "general statement of caudate function." Nowhere has Kirkby ever suggested that this is the sole function of the caudate nucleus or that the caudate nucleus is homogeneous in function. In fact, the opposite has been stated, "It is not unexpected that lesions involving different parts of the corpus striatum should vary in effect (Kirkby \& Polgar, 1974, p. 305)" and "It seems that for learning tasks the caudate is not equipotential. That is, lesioning or stimulating of specific areas of the caudate disrupts the learning of some problems but not of others (Kirkby, 1971, p. 80)."

We would like to take this opportunity to clarify another apparent misunderstanding. Winocur (1974, p. 432) reported that "Kirkby (1969) found that rats with bilateral lesions to the caudate nucleus acquired a simultaneous brightness discrimination within normal limits but were impaired when the problem was reversed. In a comparable test using the same tasks, Schwartzbaum \& Donovick (1968) reported directly opposite results."

In the Kirkby (1969) investigation, rats were tested on a traditional brightness discrimination problem requiring the subject to enter the appropriate alley of a $\mathrm{T}$ maze. The brightness discrimination problem in the Schwartzbaum and Donovick (1968) study required the animal to respond by pressing the appropriate one of two illuminated levers. However, the task was made more difficult by placing pairs of levers in the opposite arms of the $\mathrm{T}$ maze and requiring the subject to respond alternately to the correct lever in one arm and then to the correct lever in the other. The Schwartzbaum and Donovick study therefore involved not only the learning of a brightness discrimination but also the learning of a spatial alternation task. Since it has been established that caudate-lesioned rats are impaired in learning spatial alternation problems (Chorover \& Gross, 1963; Gross, Chorover, \& Cohen, 1965; Mikulas, 1966), but not in learning visual discrimination problems (Ghiselli \& Brown, 1938; Kirkby, 1969; Lashley, 1921), the deficits shown by the Schwartzbaum and Donovick rats were probably associated with the alternation rather than the discrimination component of the problem.

Clearly the experiments of Kirkby, and Schwartzbaum and Donovick did not involve what Winocur described as "a comparable test using the same task."

\section{REFERENCES}

Chorover, S. L., \& Gross, C. G. Caudate nucleus lesions: Behavioral effects in the rat. Science, 1963, 141, 826-827.

Coyle, I. R., Kirkby, R. J., \& Polgar, S. A "warm up" effect in learning by brain-damaged rats. Australian Psychologist, 1972. 7, 246.

Ghiselli, E. E., \& Brown, C. W. Subcortical mechanisms in learning. III. Brightness discrimination. Journal of Comparative Psychology, 1938, 26, 271-285.

Green, R. H., Beatty, W. W., \& Schwartzbaum, J. S. Comparative effects of septo-hippocampal and caudate lesions on avoidance behavior in rats. Journal of Comparative and Physiological Psychology, 1967, 64, 444-452.

Gross, C. G., Chorover, S. L.. \& Cohen, S. M. Caudate, cortical, hippocampal and dorsal thalamic lesions in rats: Alternation and Hebb-Williams maze performance. Neuropsychologia, 1965, 3. 53-68.

KIRKBy, R. J. Caudate nucleus lesions and perseverative behavior. Physiology and Behavior, 1969, 4, 451-454.

KIRKBY, R. J. The caudate nucleus and arousal. Unpublished PhD thesis submitted to the Department of Psychiatry. University of New South Wales, 1971.

KIRKBY, R. J. The caudate nucleus and arousal in the rat. Journal of Comparative and Physiological Psychology, 1973, 85, 82-96.

KirkBY, R. J., \& Kimble, D. P. Avoidance and escape behavior following striatal lesions in the rat. Experimental Neurology, $1968,20,215-227$.

KIrkby, R. J.. \& Polgar, S. Active avoidance in the laboratory rat following lesions of the dorsal or ventral caudate nucleus. Physiological Psychology, 1974, 2, 301-306.

LASHLEY, K. S. Studies of cerebral function in learning. No. IIIThe motor areas. Brain, 1921, 44, 255-285.

Mikulas, W. L. Effects of lights at the choice point on spatial alternation and position learning by normal rats and rats with bilateral lesions of the caudate nucleus. Psychonomic Science, 1966, 5, 275-276.

Schwartzbaum, J. S., \& Donovick, P. J. Discrimination reversal and spatial alternation associated with septal and caudate dysfunction in rats. Journal of Comparative and Physiological Psychology, 1968, 65, 83-92.

ThomAs, R. K., \& Hill, A. S. The caudate nucleus and avoidance learning: A reevaluation. Bulletin of the Psychonomic Society, 1973, 1, 346-348.

VANDERwolf, C. H. Medial thalamic functions in voluntary behavior. Canadian Journal of Psychology, 1962, 16, 318-330.

Winocur, G. Functional dissociation within the caudate nucleus of rats. Journal of Comparative and Physiological Psychology, 1974, 86, $432-439$.

Winocur, G. Comments on Kirkby and Polgar's interpretation of caudate nucleus function. Physiological Psychology, 1975, 3, 255-256.

Winocur, G., \& Mills, J. A. Effects of caudate lesions on avoidance behavior in rats. Journal of Comparative and Physiological Psychology, 1969, 68, 552-557.

(Received for publication September 8, 1975; accepted September 16, 1975.) 